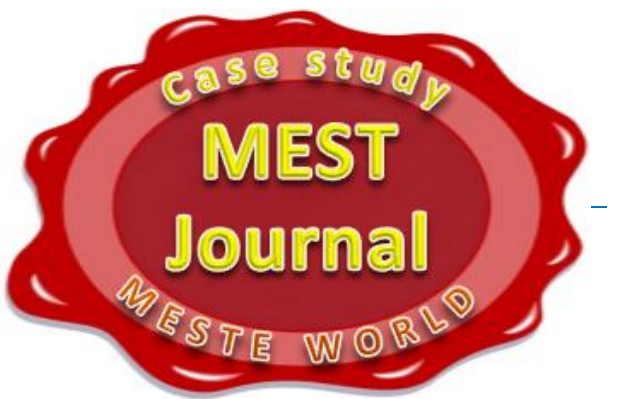

\title{
SMARTPHONE APPLICATION FOR MANAGING MISSED AND FOUND BELONGINGS
}

\author{
Zainab Abdul-Jalil Salman \\ University of Baghdad, Baghdad, Iraq \\ Omar A. Athab \\ University of Baghdad, Baghdad, Iraq \\ https://orcid.org/0000-0003-0903-9182
}

CMESTE

JEL Category: M15, 032

\begin{abstract}
Nowadays, due to our everyday stress and current stressful lifestyle, the loss of items appears a frequent issue and may be very inconvenient. In this regard, until the loT becomes part of everyday life, we can use the software as an efficient tool to assist a person's searching, verifying, and finding lost belongings. This paper presents an Android-based application that we proposed and implemented to help users find lost items. Utilizing this software will enable the subscriber to record his request to the relevant authority. In addition, a special section offers to insert a contact telephone number or email to communicate between the person who found the item and the person who lost it. During testing, among other services, the platform showed its capabilities to register and log users, releasing a lot of information of lost items and automatically forwarding lost-and-found notifications. The paper can be useful for those who deal with the application of information technology.
\end{abstract}

Keywords: Finding, Missing, Belongings, Mobile application, Android.

\section{INTRODUCTION}

We sometimes forget what happened, some of us may be robbed and it is difficult to get back our property. Lost items (for example, important documents, certificates, mobile phones, tablets, laptops, wallets, keys, luggage, jewelry) can cause stress and inconvenience, and as a person has more contact with the lost item, the degree of pain will also increase. Choosing to follow

Address of the corresponding author: Zainab Abdul-Jalil Salman 莑" zainab.abd1703@kecbu.uobaghdad.edu.iq conventional steps once assets (particularly expensive ones) is lost, for example filling an official form in the court or going to a missed and found office, possibly not enough to guarantee the recovery of the misplaced item (Harburg, Kim, Gerber, \& Zhang, 2015).

Finding and retrieving lost and lost items are timeconsuming, laborious, and a waste of money (Ahmad, Ziaullah, Rauniyar, Su, \& Zhang, 2015). A study in 2013 showed that approximately $\$ 176.9 \times 10^{9}$ was lost every year on finding missed things. Additionally, the survey showed that individuals spend around 0.5 hours weekly 
seeking wasted property (Mac, 2017). In 2018, a report done by Finance Firm in the UK stated that fraud losses in the UK exceeded $£ 1.2 \mathrm{bn}$. As said by the company, missed and robbed card cases accounted for $14 \%$ of total card fraud losses in 2018 (Saed, 2019).

Different efforts have been proposed to assist the victim in finding his belongings. In 2019, Aria Razi and colleagues suggested a smartphone application "Kembaliin" specially dedicated to helping town people solve the problem of misplaced and found belongings in public regions online (Razi \& Putra, 2020). The application paradigm plays the role of intermediary link and promotes the necessity of interchanging information between the lost (sufferer) and the helper who locates wasted items. Jiang, Mao, and Kang in their work (Jiang, Mao, \& Kang, 2019) suggests a mobile application for online misplaced and found network primarily based on digital map API records. The digital map API service analyzes the item information to add the appropriate push and praise module to grow humans' enthusiasm for returning the picked belongings. Alnaghaimshi N. I. and colleagues presented the MAFQUDAT service, which is specially designed to support users in Arabic and could be seen as a competent facility for persons who have missed or found something. This proposed application uses GPS technology consistent with IOS devices (iPad, iPod Touch, and iPhone). MAFQUDAT allows users to report lost or found items, providing a space that can reach a wider society (Alnaghaimshi, Alfayez, Alenizy, \& Almutairi, 2020). Meenakshi S. Arya and colleagues introduced the F.I.N.D application that can find misplaced things very efficiently and comfortably. Also, it may offer leads to agencies, such as NGOs or police, who spend a lot of effort finding the missing people. With this body search function, users can find lost objects found in various places (Arya, Muley, Desai, \& More, 2018).

As mentioned above, scholars used various techniques to compensate for the problem. Thus, in this work, the light is focused on allowing all users to add complaints (not restricted) and introducing a simple graphical user interface with easy-to-view information. Hence, the research aims to expediently list a complaint on the registry without really contacting a police center (thus keeping subscriber's time) and to reunite owners with lost and found items on a single platform which speeds up their search and find lost items.

\section{ARCHITECTURE AND IMPLEMENTATION}

Fig. 1 shows the steps followed in the research. The work obeys the three-layering architecture (Denko, Pečnik, \& Fister Jr, 2021) of mobile applications as described below:

- Presentation Layer - The dart language and its framework flutter in carrying out the front-end presentation layer. The responsibility of this component is bringing and interpreting data to users. This is what the handler views while using the application.

- Business logic Layer - This layer represents the adhesive between the information in the front end and the database in the back end. In this research, JSON is used for connecting the treated presentation data with the back-end infrastructure.

- Data Layer - The Firebase database is used to run this layer. It supports real-time data synchronization and stores all information in a well-defined format.

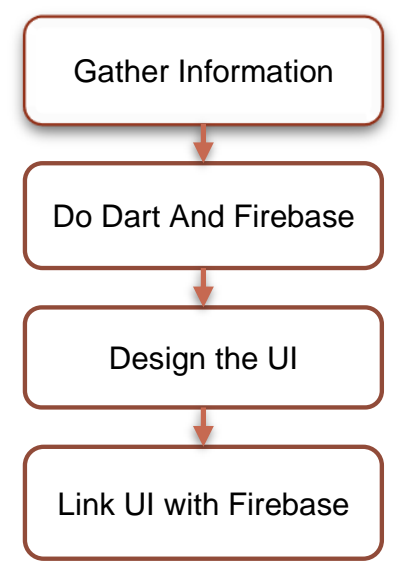

Fig. 1 Workflow diagram of the research

This application is designed to help anyone to find his/her misplaced item in an outdoor area. Furthermore, it enables registering a complaint about the loss of a thing or human: Once the user registers into account, he will be able to enter the home page and see all the posts. The subscriber will also be able to record a complaint after filling in the essential data regarding that specific object or person. Figure 2 illustrates the activity diagram of the general implementation of the application. 


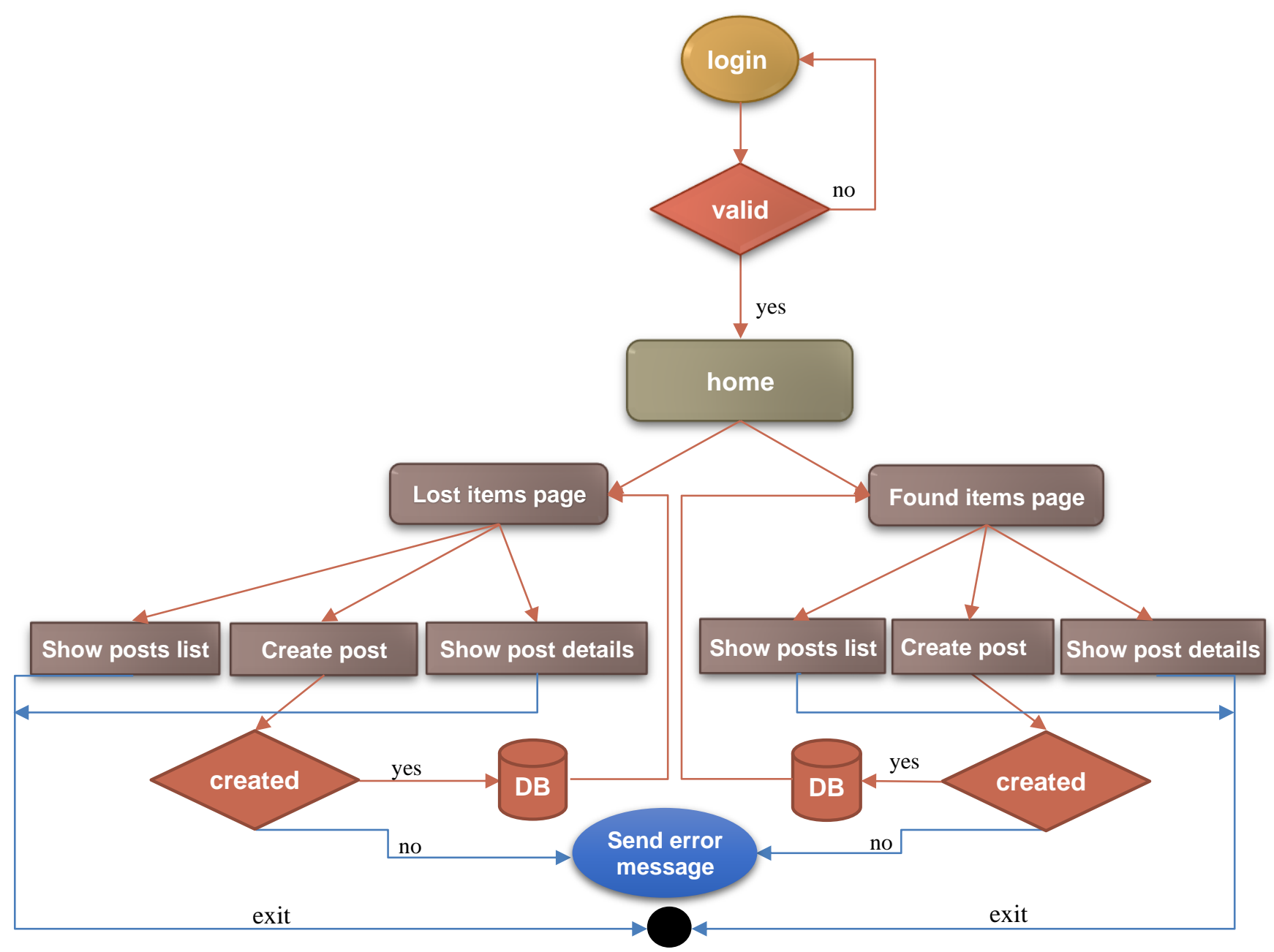

Fig 2: Activity diagram of the application

\section{RESULTS}

- Log In Page - The UI for the sign-in page of the application is shown in Figure 3, the user enters information (username \& password). If he does not have an account in the application, he will go to the register page.

- Sign Up Page - The UI for sign up Page of the application is shown in Figure 4

- Any user enters the application for the first time, he needs the sign-up step to use the app.

- Once the user signs up, he is forwarded to the log-in section to use the app.

- Home Page - The UI for the Home Page of the application is shown in Figure 5.
The main page contains two options, one leads to the found items page and the other to the lost items page. It also has a navigation bar for navigating the app pages and contains userentered information and a logout button.

- Lost Items Page - The UI for the Home Page of the application is shown in Figure 6, it contains several sections of the missing items. The user can choose a section according to his element.

- Found Items Page - The UI for Found Items Page of the application is shown in Figure 7.

It has the same UI as the Lost items page, and it contains several sections of the missing items. The user can choose a section according to his element. 
- Post creation page - The UI for the Post Creation Page of the application is shown in Figure 8.

Through this page, the user is capable to fill in his post information such as his name, city, and description of the item, whether it is missing or founding.

- Posts page - The UI for the Posts page of the application is shown in Figure 9, each section of the page displays its posts. This page will contain all the posts uploaded by users, which are of one type, for example, the display posts page of a key type.

- Post-Information Page - The UI for the Post Information Page of the application is shown in Figure 10. Once you click on any post, this page will be displayed containing all the post information that was filled out by the user.
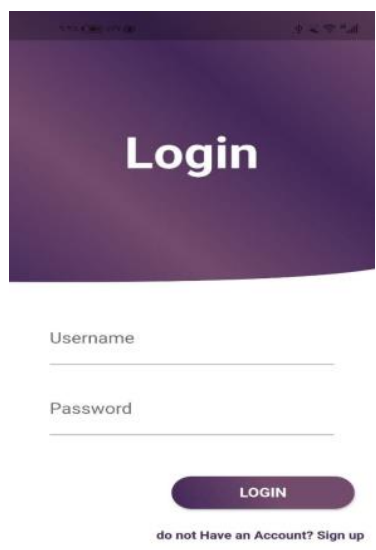

Fig.3 Sign-In Page

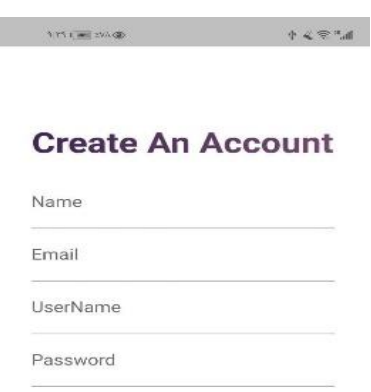

\section{SIGN UP}

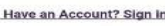

Fig.4 Sign-Up Page

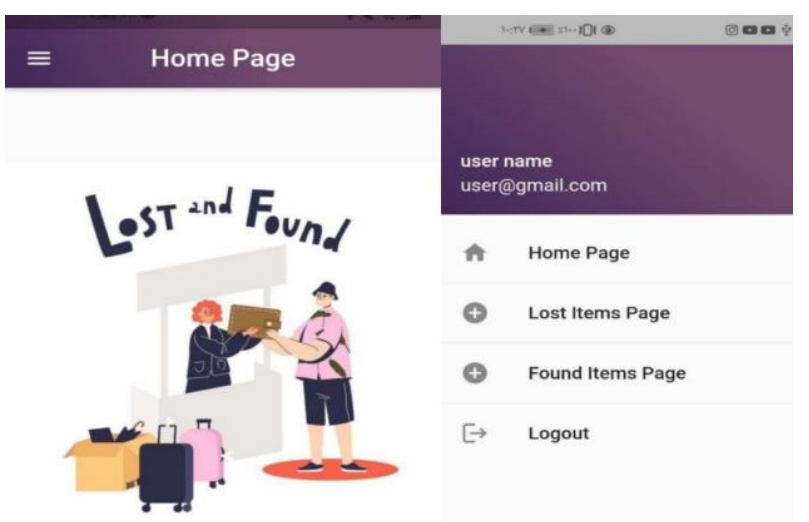

FOUND AN ITEM

LOST AN ITEM
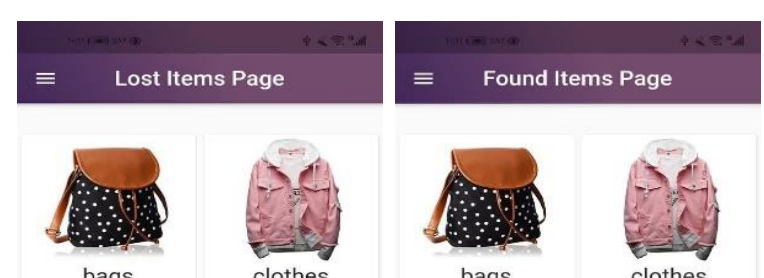

bags
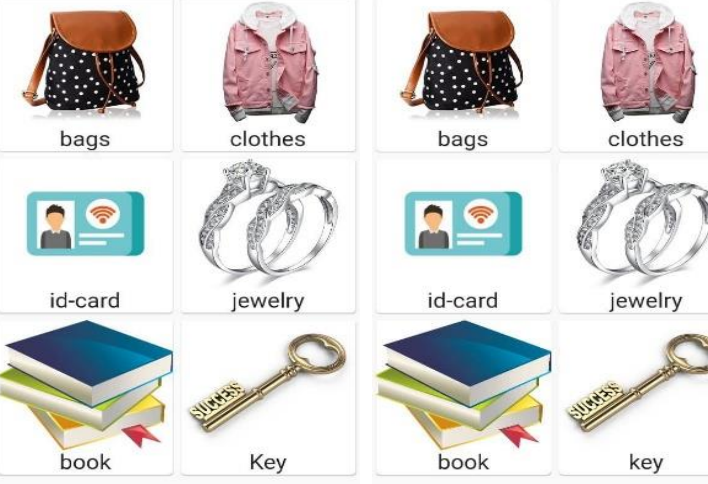

jewelry

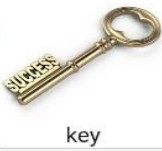

Fig. 6 Lost Items Page

Fig.7 Found items Page
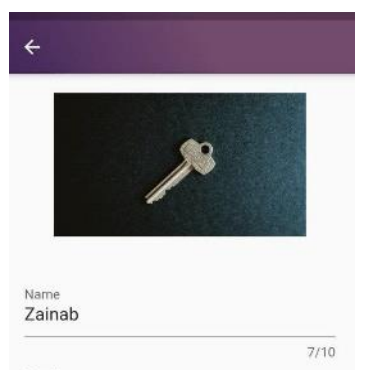

zainab@gmail.com
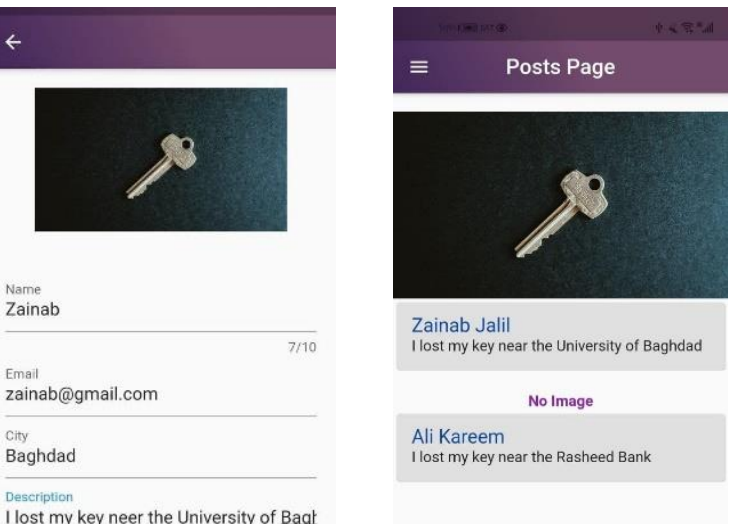

I lost my key neer the University of Bagt

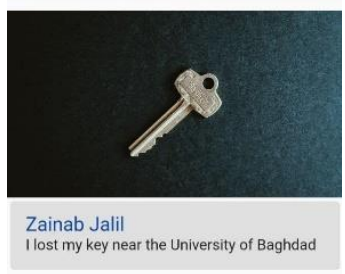

No Image

Ali Kareem

I lost my key near the Rasheed Bank

\section{(n)}

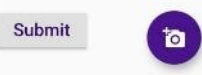

Fig8: Post creation Page

Fig9: Posts Page

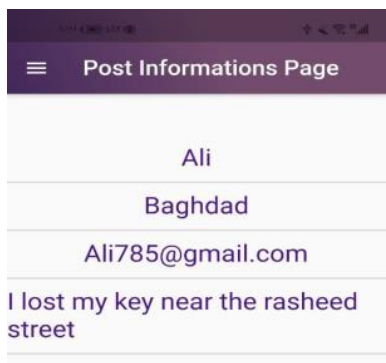

Fig. 5 Home Page

Fig10: Post Information Page 
Table 1 Functional testing

\begin{tabular}{|l|l|l|l|l|l|}
\hline \multicolumn{5}{|c|}{ Project name: Smartphones application for Announcing Missed and Found Items } \\
Test platform: Android
\end{tabular}

\section{FUNCTIONAL TESTING}

Functional testing is to prove the various tasks of the missed-and-found platform. Element by element test is used to inspect whether the application fulfills the design objectives. This process starts from the sign-in page, step by step, to ensure whether the information is consistent and can be picked up and returned smoothly. Table 1 demonstrates a scenario example for the platform usage and testing.

\section{CONCLUSIONS}

Wasting an item, particularly an important one, and having an emotional connection with us may affect emotional health. software solutions can supply answers for persons who are influenced by such losses. In response, this article implements an application to easily announce missed and found things to the broader society. The search task may take a long time, and this implantation can assist fast searches by allowing other persons to know what they are looking for; you never know who found the item and waits for it to be returned to you. The Finder application will largely reflect the active integration of the members of the society, based mainly on the participation of the user's network.

\section{WORKS CITED}

Ahmad, S., Ziaullah, M., Rauniyar, L., Su, M., \& Zhang, Y. (2015). How does matter lost and misplace items issue and its technological solutions in 2015-a review study. IOSR J. Bus. Manag. Ver. I, 17(4), 2319-7668.

Alnaghaimshi, N. I., Alfayez, G. S., Alenizy, R. A., \& Almutairi, A. (2020). Mafqudat: Arabic Smartphone Application for Reporting Lost and Found Items. 2020 3rd International Conference on Computer Applications \& Information Security (ICCAIS), (pp. 0-3).

Arya, M. S., Muley, M., Desai, P., \& More, H. (2018). An Android Based Application to Find Missing Children and Lost Belongings ( F.I.N.D.). IOSR Journal of Engineering (IOSRJEN), 11, 54-57. Retrieved from https://www.google.com/url?sa=t\&rct=j\&q=\&esrc=s\&source=web\&cd=\&ved=2ahUKEwjsqLrzs O30AhXggfOHHWSQD50QFnoECAMQAQ\&url=http\%3A\%2F\%2Fwww.iosrjen.org\%2FPapers \%2FConf.ICIATE-2018\%2FVolume-11\%2F14-5457.pdf\&usg=AOvVaw3CYB7IAZHQESvH5bbgndA5 
Denko, B., Pečnik, Š., \& Fister Jr, I. (2021). A Comprehensive Comparison of Hybrid Mobile Application Development Frameworks. International Journal of Security and Privacy in Pervasive Computing, 13(1), 78-90. doi:10.4018/IJSPPC.2021010105

Harburg, E., Kim, Y., Gerber, E. M., \& Zhang, H. (2015). CrowdFound: A mobile crowdsourcing system to find lost items on-the-go. The 33rd annual ACM conference extended abstracts on human factors in computing systems., 18, pp. 1537-1542. doi:10.1145/2702613.2732757

Jiang, L., Mao, H., \& Kang, Z. (2019). The Design of Campus Lost and Found Platform Based on Digital Map Data. 2019 International Conference on Computer Information Analytics and Intelligent Systems (CIAIS 2019), (pp. 63-67).

Mac, J. (2017, 05 02). Lost and Found: The Average American Spends 2.5 Days Each Year Looking For Lost Items Collectively Costing U.S. Households \$2.7 Billion Annually in Replacement Costs. PRNewswire.

Razi, A. A., \& Putra, R. P. (2020). The Hooked Model as Communication Strategy of 'Kembaliin' App as an Information Media for Handling Lost and Found. 2nd Social and Humaniora Research Symposium (SoRes 2019), 409, pp. 214-218.

Saed, D. (2019). Fraud The Facts 2019. Retrieved from UK Finance: https://www.ukfinance.org.uk/system/files/Fraud\%20The\%20Facts\%202019\%20\%20FINAL\%200NLINE.pdf

Received for publication: $\quad$ 13.11.2021

Revision received: $\quad 18.11 .2021$

Accepted for publication: $\quad 06.01 .2022$

\section{How to cite this article?}

Style - APA Sixth Edition:

Salman, Z. A.-J., \& Athab, O. A. (2022, 01 15). Smartphone application for managing missed and found belongings. (Z. Cekerevac, Ed.) MEST Journal, 10(1), 66-71. doi:10.12709/mest.10.10.01.08

Style - Chicago Sixteenth Edition:

Salman, Zainab Abdul-Jalil, and Omar A. Athab. 2022. "Smartphone application for managing missed and found belongings." Edited by Zoran Cekerevac. MEST Journal (MESTE) 10 (1): 66-71. doi:10.12709/mest.10.10.01.08.

Style - GOST Name Sort:

Salman Zainab Abdul-Jalil and Athab Omar A. Smartphone application for managing missed and found belongings [Journal] // MEST Journal / ed. Cekerevac Zoran. - Belgrade - Toronto : MESTE, 01 15, 2022. - 1 : Vol. 10. - pp. 66-71.

Style - Harvard Anglia:

Salman, Z. A.-J. \& Athab, O. A., 2022. Smartphone application for managing missed and found belongings. MEST Journal, 15 01, 10(1), pp. 66-71.

Style - ISO 690 Numerical Reference:

Smartphone application for managing missed and found belongings. Salman, Zainab Abdul-Jalil and Athab, Omar A. [ed.] Zoran Cekerevac. 1, Belgrade - Toronto : MESTE, 01 15, 2022, MEST Journal, Vol. 10, pp. 66-71. 